\title{
Evaluation of a Sclerotinia homoeocarpa Population with Multiple Fungicide Resistance Phenotypes Under Differing Selection Pressures
}

\author{
Hyunkyu Sang, James T. Popko Jr., and Geunhwa Jung ${ }^{\dagger}$ \\ Stockbridge School of Agriculture, University of Massachusetts, Amherst, MA 01003
}

\begin{abstract}
Dollar spot, caused by Sclerotinia homoeocarpa, is one of the most significant diseases of cool-season turfgrass on golf courses. Resistance to the benzimidazole, dicarboximide, and succinate dehydrogenase inhibitor (SDHI) classes and reduced sensitivity to the sterol-demethylation inhibitor (DMI) in S. homoeocarpa populations have been widely reported in the United States. Moreover, the occurrence of S. homoeocarpa populations with multiple fungicide resistance (MFR) is a growing problem on golf courses. The present study was undertaken to evaluate the efficacy of DMI, dicarboximide, and SDHI against a S. homoeocarpa population with MFR on a Connecticut golf course fairway from 2014 to 2016. Also, because the S. homoeocarpa population consisted of four different phenotypes with differing resistance profiles to benzimidazole, dicarboximide, and DMI, in vitro sensitivity assays were used to

understand the dynamics of the MFR population in the presence and absence of fungicide selection pressures. Results indicated that boscalid fungicide (SDHI) was able to provide an acceptable control of the MFR dollar spot population. Propiconazole or iprodione application selected isolates with both DMI and dicarboximide resistance (DMI-R/Dicar-R). In the absence of fungicide selection pressures, the percent frequency of DMI-R/ Dicar-R or DMI and benzimidazole resistance (DMI-R/Ben-R) isolates declined in the population. Out of the four phenotypes, the percent frequency of isolates with DMI, dicarboximide, and benzimidazole resistance (DMI$\mathrm{R} /$ Dicar-R/Ben-R) was the lowest in the population regardless of fungicide selection pressures. Our first report of MFR population dynamics will help develop effective strategies for managing MFR and potentially delay the emergence of future resistant populations in S. homoeocarpa.
\end{abstract}

Dollar spot, caused by an ascomycete filamentous fungus Sclerotinia homoeocarpa F.T. Bennett (now Clarireedia spp., SalgadoSalazar et al. 2018), is the most important and economically challenging turfgrass disease in the United States (Smiley et al. 2005). The disease causes considerable damage to creeping bentgrass (Agrostis stolonifera L.) and annual bluegrass (Poa annua L.) on golf course putting greens, tee boxes, and fairways (Latin 2011; Walsh et al. 1999). Multiple fungicide applications are required to maintain acceptable turf quality throughout the growing season (Walsh et al. 1999). Fungicide resistance of $S$. homoeocarpa has been confirmed in four classes of fungicides: benzimidazole, dicarboximide, demethylation inhibitor (DMI), and succinate dehydrogenase inhibitor (SDHI). Populations with multiple fungicide resistance (MFR) and multidrug resistance have been observed (Detweiler et al. 1983; Popko et al. 2018; Putman et al. 2010; Sang et al. 2015; Stephens and Kaminski 2019; Vargas et al. 1992; Warren et al. 1974).

A 2010 monitoring study reported $S$. homoeocarpa populations with a wide range of reduced sensitivities to benzimidazole, dicarboximide, and DMI fungicides on golf courses in New England (Putman et al. 2010). A portion of the golf courses included $S$. homoeocarpa populations with isolates that were resistant to iprodione and confirmed for resistance mechanisms using molecular

${ }^{\dagger}$ Corresponding author: Geunhwa Jung; E-mail: jung@umass.edu

Funding: The research was partially funded by United States Golf Association (2016-18-568). This material is based upon work supported by the National Institute of Food and Agriculture, U.S. Department of Agriculture, the Massachusetts Agricultural Experiment Station and the Stockbridge School of Agriculture at the University of Massachusetts Amherst, under project number MAS00436.

Current address for H. Sang: Department of Plant, Soil and Microbial Sciences, Michigan State University, East Lansing, 48824.

The contents are solely the responsibility of the authors and do not necessarily represent the official views of the USDA or NIFA.

Accepted for publication 24 September 2018.

() 2019 The American Phytopathological Society techniques (Putman et al. 2010; Sang et al. 2017). Briefly, the iprodione-resistant isolates harbor two types of resistance mechanisms: polymorphisms in the histidine kinase gene Shos1 (a putative target gene of dicarboximide, qualitative resistance) and overexpression of an efflux transporter ShPDR1 (quantitative resistance) (Sang et al. 2017). For a better understanding of the practical implications of iprodione resistance levels, field efficacy experiments were initiated in 2014 at a golf course with dicarboximide resistance. $S$. homoeocarpa population in this golf course had a combination of four different phenotypes with differing fungicide resistance profiles to the benzimidazole, dicarboximide, and DMI classes.

Emergence of MFR $S$. homoeocarpa isolates is an increasing problem in the turf industry (Bishop et al. 2008; Golembiewski et al. 1995; Jo et al. 2006; Koch et al. 2009; Ok et al. 2011; Putman et al. 2010; Stephens and Kaminski 2019). Therefore, an improved understanding of the dynamics of $S$. homoeocarpa populations with MFR is needed for developing effective management strategies. Rotation of different site-specific fungicide classes or tank mixing with multisite modes of action fungicides (chlorothalonil or fluazinam) is recommended for managing a fungicide-resistant $S$. homoeocarpa population or delaying the development of resistant populations (Allan-Perkins et al. in press). A further understanding of resistant population reversion, overwintering effects of previous fungicide applications, and persistence of a reverted population will help develop improved strategies to manage MFR populations and delay the emergence of MFR populations.

Our objectives of this study were (i) to evaluate field efficacy of fungicides on a $S$. homoeocarpa population with MFR in 2014, 2015 , and 2016, (ii) to investigate the dynamics of a S. homoeocarpa population with four MFR phenotypes under fungicide selection pressures, and (iii) to determine the persistence of the selected resistant populations in the absence of fungicide pressures (after overwintering).

\section{Materials and Methods}

Experimental plots. Field efficacy testing and isolate collection of $S$. homoeocarpa were conducted at a golf course fairway in Wethersfield, CT, in 2014, 2015, and 2016. The S. homoeocarpa populations exhibit differential in vitro sensitivities to benzimidazole, dicarboximide, and DMI fungicides (Table 1). Experimental 
plots in 2014 and 2015 were in the same exact fairway location (location 1, Loc 1), and the 2016 plot was located at a different area on the same fairway (location 2, Loc 2). Both plots consisted of creeping bentgrass and annual bluegrass mowed (three times per week) at fairway height $(1.3 \mathrm{~cm})$. The experimental design was a randomized complete block design with three replications. Each plot was $0.91 \times 1.83 \mathrm{~m}$ with $0.3-\mathrm{m}$ buffer strips between each plot. The sites were annually provided with 82.9 to $117.4 \mathrm{~kg}$ of N/ha, and turfgrass weeds and insects were managed by chemical controls at the discretion of the superintendent. A plant growth regulator, trinexapac-ethyl (Primo MAXX 1ME, Syngenta Crop Protection, Greensboro, NC) and multisite fungicides fluazinam (Secure, Syngenta Crop Protection) and chlorothalonil (Docket, Syngenta Crop Protection) were previously applied 2 weeks prior to 2014 initial sampling.

2014, 2015, and 2016 field efficacy. Treatments for field efficacy tests included boscalid (Emerald 70WG, BASF Corporation, Germany), iprodione (Chipco 26GT 2SC, Bayer, Germany), propiconazole (Banner MAXX II 1.3ME, Syngenta Crop Protection), and an untreated control (Table 2). Product application rates and dates are listed in Table 2. Fungicides were applied at a nozzle pressure of $276 \mathrm{kPa}$ using a $\mathrm{CO}_{2}$-pressurized boom sprayer equipped with two flat-fan XR Teejet 8004VS nozzles. Individual dollar spot infection centers per plot were counted approximately every 7 days for disease severity ratings. Area under the disease progress curve (AUDPC) values were calculated using the following formula:

$$
\mathrm{AUDPC}=\sum_{i=1}^{n_{i}-1} \frac{\left(y_{i}+y_{i+1}\right)}{2}\left(t_{i+1}-t_{i}\right)
$$

in which $y_{i}$ is the amount of disease on the $i$ th date, $t_{i}$ is $i$ th day, and $n$ is the number of dates on which dollar spot was recorded (Campbell and Madden 1990). Fisher's protected LSD was conducted to compare the square-root-transformed AUDPC values among treatments, because actual data range over several orders of magnitude (Veturi et al. 2012). All statistical analyses were performed with the JMP software package, version 10.0 (SAS Institute).

Isolate collection and in vitro fungicide sensitivity tests. $S$. homoeocarpa isolates were collected in the same method as done

Table 1. Fungicide sensitivity of Sclerotinia homoeocarpa isolates collected from locations 1 and 2 of the fairway at a golf course in Connecticut in 2014, 2015, and 2016

\begin{tabular}{lccc}
\hline & \multicolumn{3}{c}{ Sensitivity to fungicides $^{\mathbf{z}}$} \\
\cline { 2 - 4 } Phenotype name $^{\mathbf{y}}$ & DMI & Dicarboximide & Benzimidazole \\
\hline DMI-R & $\mathrm{I}$ & $\mathrm{S}$ & $\mathrm{S}$ \\
DMI-R/Dicar-R & $\mathrm{I}$ & $\mathrm{R}$ & $\mathrm{S}$ \\
DMI-R/Ben-R & $\mathrm{I}$ & $\mathrm{S}$ & $\mathrm{R}$ \\
DMI-R/Dicar-R/Ben-R & $\mathrm{I}$ & $\mathrm{R}$ & $\mathrm{R}$ \\
\hline
\end{tabular}

y Phenotypes: DMI-R = sterol-demethylation inhibitor (DMI) insensitive; DMI-R/Dicar-R = DMI and dicarboximide resistance; DMI-R/Ben-R = DMI and benzimidazole resistance; and DMI-R/Dicar-R/Ben-R = DMI, dicarboximide, and benzimidazole resistance.

${ }^{\mathrm{z}} \mathrm{I}=$ insensitive to DMI fungicides, meaning a quantitative resistance; $\mathrm{S}=$ sensitive; and $\mathrm{R}=$ resistant. in a previous study (Allan-Perkins et al. 2017). Briefly, isolates were collected immediately prior to first application of each year (2014, 2015, and 2016), 7 days after third application (2014), 7 days after second application (2015), 7 days after fourth application (2016), and 21 days after final application (2014, 2015, and 2016) to monitor changes of four isolate resistant phenotypes in the MFR population in response to fungicide applications. Also, to understand the effect of the absence of fungicide selection pressure on the MFR population, overwintering samples for 2014 and 2015 were collected in summer 2015 (same as initial samples for 2015) and summer 2016, respectively. The initial or overwintering sampling was performed when approximately 10 dollar spot infection centers per plot were observed in 2014, 2015, and 2016. Information on sampling dates is described in Table 2. Ten samples per plot in each replication (30 samples total for each sampling event) were attempted to collect from different individual infection centers in the untreated, boscalid treated (both rates), propiconazole treated (both rates), and iprodione treated plots by selecting individual grass blades representing individual dollar spot infection centers that exhibited bleached hourglass lesions. For sampling 7 days after treatment (7DAT), grass blades with active mycelia or recently developed lesions were selected. A total of 20 to 30 isolates from each untreated and fungicide treated plot summed over all three replicated areas for the three years' studies were obtained, except for plots treated with propiconazole at $0.5 \mathrm{~kg}$ of active ingredient (a.i.)/ha $(n=17)$ and $1.0 \mathrm{~kg}$ of a.i./ha $(n=18)$ and with iprodione $(n=18)$ in 2015-7DAT (owing to unfavorable conditions). In addition, we were unable to collect fresh dollar spot samples from boscalid treated plots (both rates) in 2015-7DAT owing to fungicide effectiveness.

Fungal isolation followed the procedures according to Popko et al. (2012). S. homoeocarpa was isolated on acidified potato dextrose agar (PDA; $39 \mathrm{~g}$ of PDA, Difco Laboratories, Detroit, MI; $1 \mathrm{ml}$ of $85 \%$ lactic acid, Fisher Scientific, Hampton, NH; and 1 liter of distilled water) and transferred to PDA and grown for 2 to 3 days at 22 to $24^{\circ} \mathrm{C}$ for in vitro assays.

Pure cultures of $S$. homoeocarpa were used for in vitro sensitivity assays on PDA amended with the discriminatory concentration of propiconazole $(1 \mu \mathrm{g} / \mathrm{ml})$, iprodione $(10 \mu \mathrm{g} / \mathrm{ml})$, and thiophanatemethyl $(1,000 \mu \mathrm{g} / \mathrm{ml})$ previously chosen (Jo et al. 2006; Popko et al. 2013; Sang et al. 2017). Commercial formulations of each fungicide were added to autoclaved PDA that had been cooled to 55 to $58^{\circ} \mathrm{C}$. Nonamended PDA were poured into $90-\mathrm{mm}$ Petri dishes (Krackeler Scientific, Albany, NY), and propiconazole, iprodione, and thiophanate-methyl amended PDA were poured into $60-\mathrm{mm}$ Petri dishes (Krackeler Scientific). Agar plugs (5 $\mathrm{mm}$ in diameter) from pure cultures of $S$. homoeocarpa isolates were placed on the center of fungicide amended and nonamended PDA Petri plates. The fungal isolates were replicated twice on fungicide amended and nonamended PDA plates. The four different phenotypes of the isolates: DMI insensitive (DMI-R), DMI and dicarboximide resistance (DMI-R/Dicar-R), DMI and benzimidazole resistance (DMI$\mathrm{R} /$ Ben-R), and DMI, dicarboximide, and benzimidazole resistance (DMI-R/Dicar-R/Ben-R) were qualitatively determined after 2 days of incubation by the ability to grow on the previously described discriminatory concentrations of propiconazole, iprodione, or

Table 2. List of treatments applied, rates, and dates applied and sampled on location 1 of the fairway in 2014 and 2015 and location 2 of the fairway in 2016

\begin{tabular}{lcccccccc}
\hline & & \multicolumn{3}{c}{ Application dates } & & \multicolumn{3}{c}{ Sampling dates } \\
\cline { 3 - 5 } Treatments & Rate (kg of a.i./ha) & $\mathbf{2 0 1 4}$ & $\mathbf{2 0 1 5}$ & $\mathbf{2 0 1 6}$ & & $\mathbf{2 0 1 4}$ & $\mathbf{2 0 1 5}$ \\
\hline Untreated & & $\ldots$ & $\ldots$ & $\ldots$ & & $6 / 16,8 / 6,9 / 5$ & $8 / 18,9 / 18,10 / 5,6 / 6 / 16^{z}$ & $6 / 6,8 / 18,9 / 1$ \\
Iprodione & 3.05 & $6 / 16,7 / 8,7 / 30,8 / 19$ & $8 / 18,9 / 11$ & $6 / 6,6 / 30,7 / 21,8 / 11$ & & $6 / 16,8 / 6,9 / 5$ & $8 / 18,9 / 18,10 / 5,6 / 6 / 16$ & $6 / 6,8 / 18,9 / 1$ \\
Propiconazole & 0.5 & $6 / 16,7 / 8,7 / 30,8 / 19$ & $8 / 18,9 / 11$ & $6 / 6,6 / 30,7 / 21,8 / 11$ & & $6 / 16,8 / 6,9 / 5$ & $8 / 18,9 / 18,10 / 5,6 / 6 / 16$ & $6 / 6,8 / 18,9 / 1$ \\
& 1.0 & $6 / 16,7 / 8,7 / 30,8 / 19$ & $8 / 18,9 / 11$ & $6 / 6,6 / 30,7 / 21,8 / 11$ & & $6 / 16,8 / 6,9 / 5$ & $8 / 18,9 / 18,10 / 5,6 / 6 / 16$ & $6 / 6,8 / 18,9 / 1$ \\
Boscalid & 0.28 & $6 / 16,7 / 8,7 / 30,8 / 19$ & $8 / 18,9 / 11$ & $6 / 6,6 / 30,7 / 21,8 / 11$ & & $6 / 16,8 / 6,9 / 5$ & $8 / 18,9 / 18,10 / 5,6 / 6 / 16$ & $6 / 6,8 / 18,9 / 1$ \\
& 0.38 & $6 / 16,7 / 8,7 / 30,8 / 19$ & $8 / 18,9 / 11$ & $6 / 6,6 / 30,7 / 21,8 / 11$ & & $6 / 16,8 / 6,9 / 5$ & $8 / 18,9 / 18,10 / 5,6 / 6 / 16$ & $6 / 6,8 / 18,9 / 1$ \\
\hline
\end{tabular}

y No fungicide application was made on untreated plots.

${ }^{\mathrm{z}}$ Overwintered samples were collected on location 1 of the fairway in 2016. 
Table 3. ANOVA of area under disease progress curve (AUDPC) values of dollar spot on location 1 (Loc 1) of the fairway in 2014 and 2015 and location 2 (Loc 2) of the fairway in 2016

\begin{tabular}{lcccc}
\hline & & \multicolumn{3}{c}{ AUDPC $^{\mathbf{z}}$} \\
\cline { 3 - 5 } Treatments & Rate (kg of a.i./ha) & 2014-Loc 1 & 2015-Loc 1 & 2016-Loc 2 \\
\hline Untreated & $\ldots$ & $5,906 \mathrm{a}$ & $1,041 \mathrm{a}$ & $11,211 \mathrm{a}$ \\
Iprodione & 3.05 & $1,410 \mathrm{bc}$ & $378 \mathrm{bc}$ & $7,022 \mathrm{~b}$ \\
Propiconazole & 0.5 & $2,037 \mathrm{~b}$ & $537 \mathrm{ab}$ & $5,922 \mathrm{~b}$ \\
& 1.0 & $1,033 \mathrm{bc}$ & $168 \mathrm{bc}$ & $5,051 \mathrm{~b}$ \\
Boscalid & 0.28 & $1,362 \mathrm{bc}$ & $145 \mathrm{bc}$ & $2,299 \mathrm{c}$ \\
& 0.38 & $378 \mathrm{c}$ & $83 \mathrm{c}$ & $1,896 \mathrm{c}$ \\
\hline
\end{tabular}

${ }^{\mathrm{z}}$ AUDPC represents mean number of dollar spot infection centers rated from 16 June to 10 Sept. 2014, 18 Aug. to 5 Oct. 2015, and 6 June to 1 Sept. 2016. Data were square-root transformed prior to analysis, but actual AUDPC values are shown. Means in a column followed by the same letter are not significantly different according to Fisher's protected LSD test $(\alpha=0.05)$. thiophanate-methyl. The percentage of the four phenotypes per plot was calculated as follows: (number of each isolate phenotype/total number of isolates) $\times 100$. HRI11 (DMI-R/Ben-R), CT47 (DMI-R/ Dicar-R), and sensitive HRS10 (DMI-S/Ben-S) were included as reference strains in this study (Sang et al. 2015; Sang et al. 2017).

Fisher's protected LSD was conducted to compare percentage of four isolate phenotypes within a sample time. Repeated measures multivariate analysis of variance (MANOVA) was performed on the isolate phenotype percentages for each treatment from 2014-Initial to 2016-Initial at Loc 1 and from 2016-Initial to 2016-Final at Loc 2.

\section{Results}

Field efficacy. Dollar spot infection centers were observed in early to mid-June in 2014 and 2016 but were not observed until midAugust in 2015. The number of dollar spot infection centers on the untreated plots increased from late July to early September in 2014

\section{Untreated}

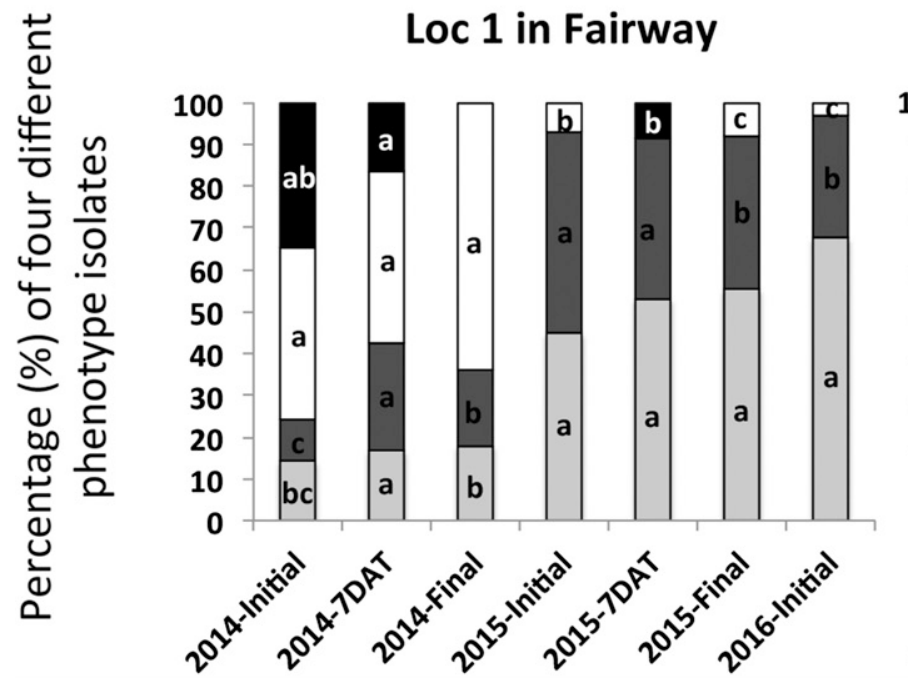

\section{Loc 2 in Fairway}

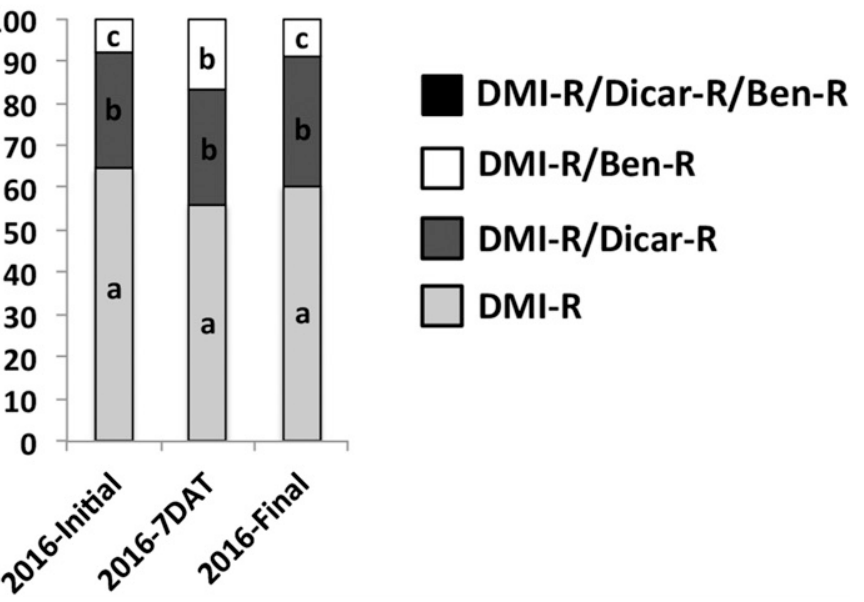

Fig. 1. Isolate phenotype percentages on untreated plots on location 1 (Loc 1) of the fairway in 2014, 2015, and 2016-Initial and on location 2 (Loc 2) of the fairway in 2016 . Initial, 7DAT, and Final refer to initial sampling before fungicide application, 7 days after treatment of fungicide, and 21 days after final treatment of fungicide, respectively. Isolate phenotypes: DMI-R = sterol-demethylation inhibitor (DMI) insensitive; DMI-R/Dicar-R = DMI and dicarboximide resistance; DMI-R/Ben-R = DMI and benzimidazole resistance; and DMI-R/Dicar-R/Ben-R = DMI, dicarboximide, and benzimidazole resistance. Means followed by the same letter within a sample time are not significantly different according to Fisher's protected LSD test $(\alpha=0.05)$.

Boscalid (0.28 kg a.i./ha)

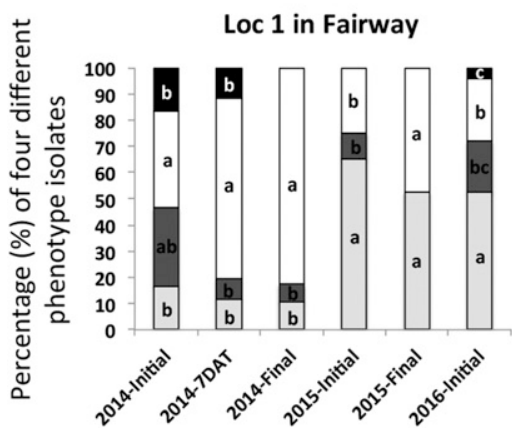

Loc 2 in Fairway

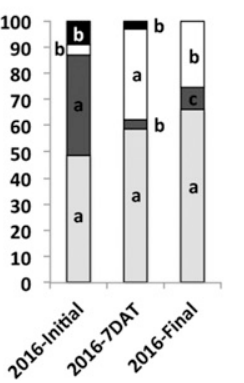

Boscalid (0.38 kg a.i./ha)

Loc 1 in Fairway

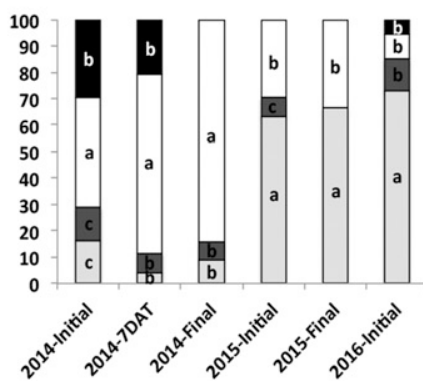

Loc 2 in Fairway

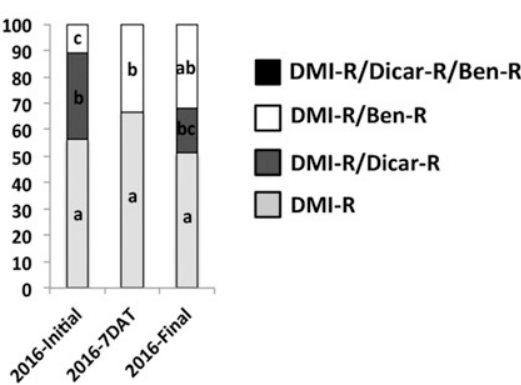

Fig. 2. Isolate phenotype percentages on boscalid ( 0.28 and $0.38 \mathrm{~kg}$ of a.i./ha) treated plots on location 1 (Loc 1) of the fairway in 2014, 2015, and 2016-Initial and on location 2 (Loc 2) of the fairway in 2016. Initial, 7DAT, and Final refer to initial sampling before fungicide application, 7 days after treatment of fungicide, and 21 days after final treatment of fungicide, respectively. Isolate phenotypes: DMI-R = sterol-demethylation inhibitor (DMI) insensitive; DMI-R/Dicar-R $=\mathrm{DMI}$ and dicarboximide resistance; $\mathrm{DMI}-\mathrm{R} / \mathrm{Ben}-\mathrm{R}=\mathrm{DMI}$ and benzimidazole resistance; and DMI-R/Dicar-R/Ben-R = DMI, dicarboximide, and benzimidazole resistance. Means followed by the same letter within a sample time are not significantly different according to Fisher's protected LSD test $(\alpha=0.05)$. 
and from early July to August in 2016, but unfavorable conditions for disease development in 2015 caused lower dollar spot severity.

The square-root-transformed AUDPC values were significantly different among treatments for all three years $(P<0.001)$. In 2014 , boscalid $(0.38 \mathrm{~kg}$ of a.i./ha) provided the best dollar spot control. In 2015, all treatments except propiconazole ( $0.5 \mathrm{~kg}$ of a.i./ha) controlled dollar spot better than the untreated control. In 2016, the AUDPC values of both rates of boscalid were significantly lower than the values of propiconazole (both rates) and iprodione. Overall, boscalid $(0.38 \mathrm{~kg}$ of a.i./ha) controlled dollar spot consistently better than all other treatments on the MFR population (Table 3 ).

Monitoring the MFR populations with four resistance phenotypes in the presence and absence of fungicide selection pressures. The 2014-Initial S. homoeocarpa population at Loc 1, likely affected by previous fungicide applications, displayed a higher percentage of DMI-R/Ben-R and DMI-R/Dicar-R/Ben-R isolates than the percentage of DMI-R and DMI-R/Dicar-R isolates. The 2016-Initial sampling at Loc 2 had a higher percentage of DMI-R isolates than DMI-R/Dicar-R isolates (except for boscalid at $0.28 \mathrm{~kg}$ of a.i./ha treated plots), and the DMI-R/Ben-R or DMI-R/Ben-R/Dicar-R isolate phenotype was at the lowest percentage among all isolate phenotypes or was absent. DMI-R/Ben-R/Dicar-R isolates disappeared over the growing season in 2014 and 2016.

The percentage of DMI-R/Ben-R isolates in the untreated plots decreased and the percentage of DMI-R isolates increased after 2014-15 overwintering. The phenotypic population structure on the untreated plots in 2015 at Loc 1 showed a similar percentage to the initial population in 2016 at Loc 2, despite these being in different plot locations. Isolate phenotype percentage on the untreated plots did not significantly change during the 2016 growing season according to repeated measures MANOVA using Wilks' lambda test $(P=$ $0.56)$. This was the only treatment that did not significantly change from the initial to final sample times in either plot location (Fig. 1).

The DMI-R/Ben-R isolates were observed in all sample times on both rates of boscalid treated plots. Boscalid provided excellent control of dollar spot in 2015, and dollar spot lesions with active mycelia were not observed on either rate of boscalid treated plots at the 20157DAT sample time. The percentage of DMI-R/Ben-R isolates was

Propiconazole (0.5 kg a.i./ha)

Propiconazole (1 kg a.i./ha)

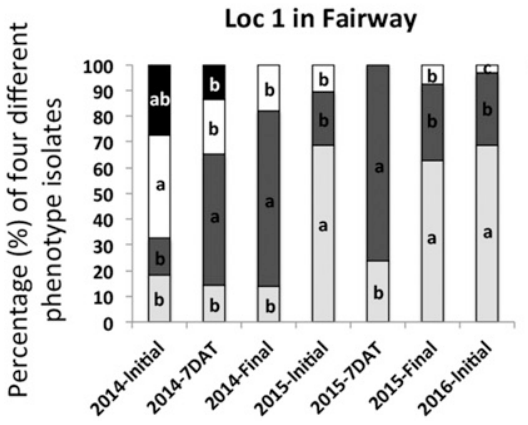

Loc 2 in Fairway

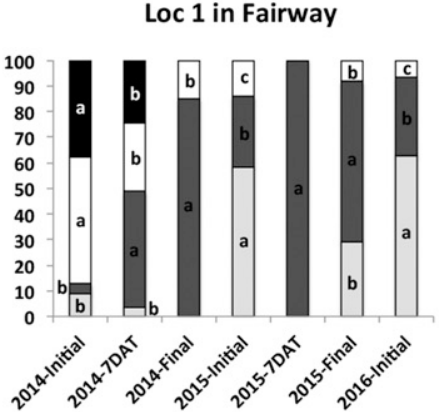

Loc 2 in Fairway
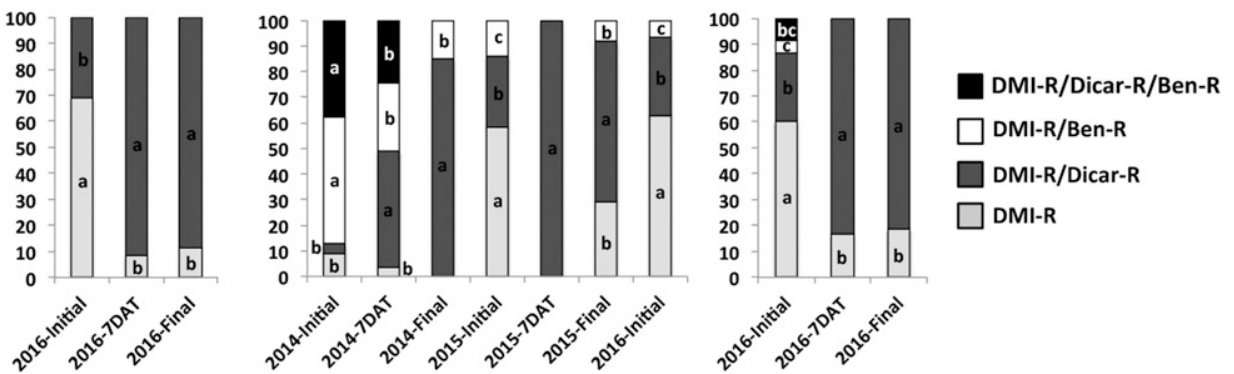

Fig. 3. Isolate phenotype percentages on propiconazole ( 0.5 and $1.0 \mathrm{~kg}$ of a.i./ha) treated plots on location 1 (Loc 1) of the fairway in 2014, 2015, and 2016-Initial and on location 2 (Loc 2) of the fairway in 2016. Initial, 7DAT, and Final refer to initial sampling before fungicide application, 7 days after treatment of fungicide, and 21 days after final treatment of fungicide, respectively. Isolate phenotypes: $D M I-R=$ sterol-demethylation inhibitor (DMI) insensitive; $D M I-R / D i c a r-R=D M I$ and dicarboximide resistance; $D M I-R / B e n-R=D M I$ and benzimidazole resistance; and DMI-R/Dicar-R/Ben-R = DMI, dicarboximide, and benzimidazole resistance. Means followed by the same letter within a sample time are not significantly different according to Fisher's protected LSD test $(\alpha=0.05)$.

\section{Iprodione (3.05 kg a.i./ha)}

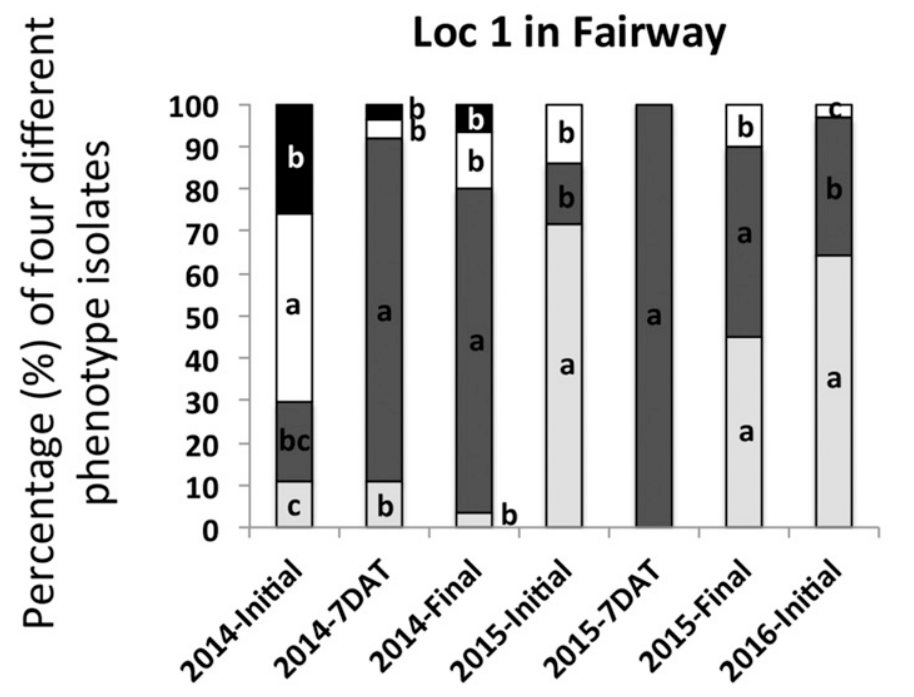

Loc 2 in Fairway

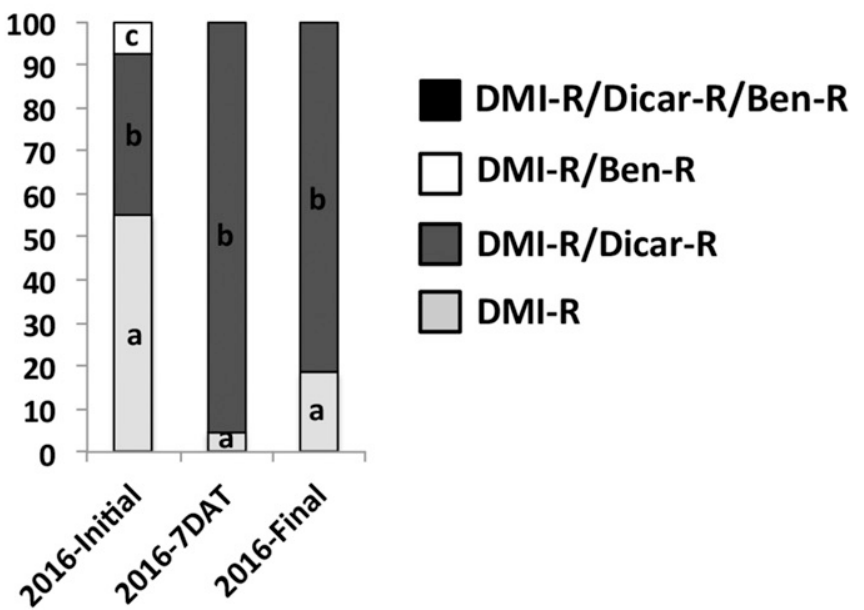

Fig. 4. Isolate phenotype percentages on iprodione (3.05 kg of a.i.//ha) treated plots on location 1 (Loc 1) of the fairway in 2014, 2015, and 2016-Initial and on location 2 (Loc 2) of the fairway in 2016. Initial, 7DAT, and Final refer to initial sampling before fungicide application, 7 days after treatment of fungicide, and 21 days after final treatment of fungicide, respectively. Isolate phenotypes: DMI-R = sterol-demethylation inhibitor (DMI) insensitive; DMI-R/Dicar-R $=\mathrm{DMI}$ and dicarboximide resistance; $\mathrm{DMI}-\mathrm{R} / \mathrm{Ben}-\mathrm{R}=\mathrm{DMI}$ and benzimidazole resistance; and DMI-R/Dicar-R/Ben-R $=\mathrm{DMI}$, dicarboximide, and benzimidazole resistance. Means followed by the same letter within a sample time are not significantly different according to Fisher's protected LSD test $(\alpha=0.05)$. 
decreased after overwintering in 2014-15 and 2015-16 at Loc 1 . The percentage of DMI-R isolates increased after overwintering in 2014-15 at Loc 1. The percentage of DMI-R/Dicar-R isolates declined or was not detected by both rates of boscalid treatments at both locations (Fig. 2).

The percentage of DMI-R/Dicar-R isolates increased at 2014-, 2015-, and 2016-7DAT on propiconazole (both rates) and iprodione treated plots. Conversely, the percentage of DMI-R/Ben-R and DMI$\mathrm{R}$ decreased or was eliminated by propiconazole (both rates) or iprodione treatments. After overwintering, the percentage of DMI-R/ Dicar-R isolates decreased, but the percentage of DMI-R isolates increased in every sample time except for 2016-Initial sample time on the propiconazole $(0.5 \mathrm{~kg}$ of a.i./ha) treated plots at Loc 1 (Figs. 3 and 4).

\section{Discussion}

In this study, $S$. homoeocarpa MFR population dynamics in response to fungicides with different modes of action and changes in fungicide sensitivity over the winter (in the absence of fungicide treatments) are characterized. These results indicate (i) boscalid $(0.38 \mathrm{~kg}$ of a.i./ha) controlled the MFR population, but iprodione and propiconazole $(0.5 \mathrm{~kg}$ of a.i./ha) controlled dollar spot poorly; (ii) DMI-R/Dicar-R isolates were most frequently selected by iprodione or propiconazole applications; and (iii) DMI-R/Dicar-R or DMI-R/Ben-R isolates decreased after overwintering. DMI-R/ Dicar-R/Ben-R isolates were the lowest in frequency regardless of fungicide treatments and untreated.

All $S$. homoeocarpa isolates collected from Wethersfield Country Club (WCC) were insensitive to the DMI fungicide class. Constant selection pressure (an average of three DMI applications per year according to superintendent spray records) may have contributed to a unimodal DMI-insensitive population distribution at WCC. Popko et al. (2012) also observed the highly homogenous and unimodal distribution of $S$. homoeocarpa population with DMI insensitivity in Wintonbury Hills Golf Club (Bloomfield, CT). This population was also exposed to constant and high selection pressure (an average of five DMI applications per year). The DMI-R phenotype in the current study was dominant among four different isolate phenotypes in the absence of selection pressure, untreated plots and all overwintered, which might be the most competitive within the population. DMI-insensitive strains in some fungal species are less competitive than sensitive strains (Al-Mughrabi and Gray 1995; Holmes and Eckert 1995; Koller and Scheinpflug 1987). However, Allan-Perkins et al. (2017) reported a persistence of DMI-insensitive S. homoeocarpa isolates at Hickory Ridge Country Club (Amherst, MA) following overwintering, when a high propiconazole rate $(0.88 \mathrm{~kg}$ of a.i./ha) was applied in the previous year. These results revealed that the increased frequency or persistence of DMI-R isolates following winter is likely owing to the absence of fungicide-sensitive isolates and presence of potentially less competitive double or triple MFR isolates.

The DMI-R/Ben-R phenotype stayed at a higher frequency on the untreated plot and boscalid treated plots (both rates) in 2014. The persistence of the phenotype during the growing season indicated that the DMI-R/Ben-R phenotype might have no fitness penalty. Botrytis cinerea benzimidazole-resistant field strains have been observed to persist without selection pressure, suggesting that benzimidazoleresistant isolates may not suffer a fitness penalty (Myresiotis et al. 2007). Furthermore, benzimidazole-resistant Venturia inaequalis strains were as competitive as the sensitive strains under the absence of selection pressure (McGee and Zuck 1981). In the current study, DMI-R/Ben-R isolates existed with small proportion regardless of fungicide treatments after overwintering. Because DMI-R phenotype is the most competitive among the phenotypes, the DMI-R/Ben-R phenotype was lower frequency than the DMI-R phenotype despite the DMI-R/Ben-R phenotype having no fitness penalty.

After application of iprodione or propiconazole, the percentage of DMI-R/Dicar-R isolates significantly increased, which most likely caused reduced dicarboximide or DMI efficacy in the population. The number of dollar spot infection centers infected with
DMI-R/Dicar-R isolates increased over the growing season owing to continuous selection pressure with the same mode of action fungicide and less competition from isolates with different phenotypes, except for 2015-Final owing to the limited selection pressure, as fungicides were only applied twice in 2015. The DMI-R/Dicar-R isolates at WCC were previously confirmed to contain two fungicide resistance mechanisms: a mutation (I366N) in the histidine kinase gene Shos 1 conferring iprodione resistance and overexpression of the multidrug transporter $S h P D R 1$, which confers reduced sensitivity to propiconazole, iprodione, and boscalid (Sang et al. 2015, 2017). These two resistance mechanisms together might play a role in the selection of DMI-R/Dicar-R isolates by iprodione or propiconazole. However, there might be additional unknown resistance factors contributing to the selection of DMI-R/Dicar-R isolates by propiconazole because all other isolate phenotypes in Loc 1 and 2 were insensitive to propiconazole. Because histidine kinase regulates the activity of a response regulator $\mathrm{Skn} 7$, which is known to be associated with the redox-sensitive transcription factor Yap1 mediating the sensitivity to DMI fungicides (Li et al. 1998; Mulford and Fassler 2011; Paul et al. 2015), the mutation in histidine kinase might affect the sensitivity of DMI-R/Dicar-R isolates to DMI fungicides. Decreased DMI-R/ Dicar-R isolates and increased DMI-R isolates on propiconazole or iprodione treated plots following overwintering could be owing to DMI-R/Dicar-R isolates that were less competitive than DMI-R isolates in the absence of fungicide pressure. An in vitro competition study between dicarboximide-sensitive and -resistant $B$. cinerea strains indicated that the proportion of dicarboximide-resistant strains declined without dicarboximide exposure (Gullino and Garibaldi 1981). Dicarboximide-resistant $B$. cinerea strains with some mutation(s) in a target histidine kinase gene contributed to hypersensitivity to osmotic stress and reduced fitness (Fillinger et al. 2012). Some of DMI-R/Dicar-R isolates with loss of function mutation (s) in Shos 1 may have existed in the population and declined after overwintering.

The initial S. homoeocarpa population in 2014, prior to any treatments in our study, contained a high percentage of DMI-R/Ben-R and DMI-R/Dicar-R/Ben-R isolates. Chlorothalonil and fluazinam were applied at Loc 1 in 20142 weeks prior to the 2014 initial sampling according to fungicide spray records obtained from the superintendent. Application of these multisite contact fungicides may have contributed to the initial proportions of the phenotypes in 2014, but further field and lab experiments will be necessary to determine the reasons for the proportion of phenotypes in 2014-Initial. High frequency of DMI-R/Dicar-R/Ben-R isolates in the initial plots decreased or were not detected during the period of our studies regardless of selection pressure. The reduction or absence of this phenotype may be owing to reduced fitness and/or competitiveness by mutations in both the benzimidazole and dicarboximide target genes. The dual benzimidazole and dicarboximide-resistant Monilinia fructicola isolates were also less competitive than single fungicideresistant isolates (Sanoamuang and Gaunt 1995).

Investigating the changes of the $S$. homoeocarpa population with four different resistant phenotypes by fungicide pressures and overwintering effects provides valuable information to turf practitioners for effective dollar spot management and potentially in other pathogenic crop systems. Vargas et al. (1992) stated S. homoeocarpa with DMI, benzimidazole, and dicarboximide resistance may pose the most difficult resistance control problem. However, the reduction of these MFR isolates without fungicide pressure implies that optimizing cultural practices to reduce fungicide applications is crucial for preventing further development of "super" MFR $S$. homoeocarpa isolates such as the $B$. cinerea isolate with resistance to seven different site-specific fungicides (Fernández-Ortuño et al. 2015).

\section{Acknowledgments}

We appreciate the generosity of Allen Woodward from Wethersfield Country Club for providing and maintaining the research area used in this study. We thank our lab members, Elisha Allan-Perkins, and visiting scholars Junghan Lee, Sanguk Park, and Dayeon Park for help with the lab and field work. 


\section{Literature Cited}

Al-Mughrabi, K. I., and Gray, A. B. 1995. Competition between triadimefonsensitive and triadimefon-resistant isolates of Erysiphe gramminis f. sp. tritici. Plant Dis. 79:709-712.

Allan-Perkins, E., Campbell-Nelson, K., Popko, J., Sang, H., and Jung, G. 2017. Investigating selection of demethylation inhibitor fungicide-insensitive Sclerotinia homoeocarpa isolates by boscalid, flurprimidol, and paclobutrazol. Crop Sci. 57: S-301-S-309.

Allan-Perkins, E., Hulvey, J., Popko, J., Mitkowski, N., Vargas, J., and Jung, G. In press. Fungicide resistance in turfgrass pathogens. In: Fungicide Resistance in North America, 2nd ed. K. L. Stevenson, M. T. McGrath, and C. A. Wyenandt, eds. The American Phytopathological Society, St. Paul, MN.

Bishop, P., Sorochan, J., Ownley, B. H., Samples, T. J., Windham, A. S., Windham, M. T., and Trigiano, R. N. 2008. Resistance of Sclerotinia homoeocarpa to iprodione, propiconazole, and thiophanate-methyl in Tennessee and northern Mississippi. Crop Sci. 48:1615-1620.

Campbell, C. L., and Madden, L. V. 1990. Introduction to Plant Disease Epidemiology. Wiley, New York, NY.

Detweiler, A. R., Vargas, J. M. J., and Danneberger, T. K. 1983. Resistance of Sclerotinia homoeocarpa to iprodione and benomyl. Plant Dis. 67:627-630.

Fernández-Ortuño, D., Grabke, A., Li, X., and Schnabel, G. 2015. Independent emergence of resistance to seven chemical classes of fungicides in Botrytis cinerea. Phytopathology 105:424-432.

Fillinger, S., Ajouz, S., Nicot, P., Leroux, P., and Bardin, M. 2012. Functional and structural comparison of pyrrolnitrin- and iprodione-induced modifications in the class III histidine-kinase Bos1 of Botrytis cinerea. PLoS One 7:e42520.

Golembiewski, R. C., Vargas, J. M., Jones, A. L., and Detweiler, A. R. 1995. Detection of demethylation inhibitior (DMI) resistance in Sclerotinia homoeocarpa populations. Plant Dis. 79:491-493.

Gullino, M. L., and Garibaldi, A. 1981. Biological properties of dicarboximideresistant strains ot Botrytis cinerea Pers. Phytopathol. Mediterr. 20:117-122.

Holmes, G. J., and Eckert, J. W. 1995. Relative fitness of imazalil-resistant and -sensitive biotypes of Penicillium digitatum. Plant Dis. 79:1068-1073.

Jo, Y., Niver, A., Rimelspach, J., and Boehm, M. J. 2006. Fungicide sensitivity of Sclerotinia homoeocarpa from golf courses in Ohio. Plant Dis. 90:807-813.

Koch, P., Grau, C., Jo, Y. K., and Jung, G. 2009. Thiophanate-methyl and propiconazole sensitivity in Sclerotinia homoeocarpa populations from golf courses in Wisconsin and Massachusetts. Plant Dis. 93:100-105.

Koller, W., and Scheinpflug, H. 1987. Fungal resistance to sterol biosynthesis inhibitors: A new challenge. Plant Dis. 71:1066-1074.

Latin, R. 2011. A Practical Guide to Turfgrass Fungicides. American Phytopathological Society, St. Paul, MN.

Li, S., Ault, A., Malone, C. L., Raitt, D., Dean, S., Johnston, L. H., Deschenes, R. J., and Fassler, J. S. 1998. The yeast histidine protein kinase, Sln1p, mediates phosphotransfer to two response regulators, Ssk1p and Skn7p. EMBO J. 17: 6952-6962.

McGee, D. C., and Zuck, M. G. 1981. Competition between benomyl-resistant and sensitive strains of Venturia inaequalis on apple seedlings. Phytopathology 71: 529-532.

Mulford, K., and Fassler, J. 2011. Association of the Skn7 and Yap1 transcription factors in the Saccharomyces cerevisiae oxidative stress response. Eukaryot. Cell 10:761-769.
Myresiotis, C. K., Karaoglanidis, G. S., and Tzavella-Klonari, K. 2007. Resistance of Botrytis cinerea isolates from vegetable crops to anilinopyrimidine, phenylpyrrole, hydroxyanilide, benzimidazole, and dicarboximide fungicides. Plant Dis. 91:407-413.

Ok, C.-H., Popko, J. T., Campbell-Nelson, K., and Jung, G. 2011. In vitro assessment of Sclerotinia homoeocarpa resistance to fungicides and plant growth regulators. Plant Dis. 95:51-56.

Paul, S., Doering, T. L., and Moye-Rowley, W. S. 2015. Cryptococcus neoformans Yap1 is required for normal fluconazole and oxidative stress resistance. Fungal Genet. Biol. 74:1-9.

Popko, J. T., Ok, C., Campbell-Nelson, K., Hulvey, J., and Jung, G. 2013. Qualitative in vitro detection of propiconazole field resistant Sclerotinia homoeocarpa isolates. Int. Turfgrass Soc. Res. J. 12:103-109.

Popko, J. T., Ok, C., Campbell-Nelson, K., and Jung, G. 2012. The association between in vitro propiconazole sensitivity and field efficacy of five New England Sclerotinia homoeocarpa populations. Plant Dis. 96:552-561.

Popko, J. T., Sang, H., Lee, J., Yamada, T., Hoshino, Y., and Jung, G. 2018 Resistance of Sclerotinia homoeocarpa field isolates to succinate dehydrogenase inhibitor fungicides. Plant Dis. 102:2625-2631.

Putman, A. I., Jung, G., and Kaminski, J. E. 2010. Geographic distribution of fungicide-insensitive Sclerotinia homoeocarpa isolates from golf courses in the northeastern United States. Plant Dis. 94:186-195.

Salgado-Salazar, C., Beirn, L. A., Ismaiel, L., Boehm, M. J., Carbone, I., Putman, A. I., Tredway, L. P., Clarke, B. B., and Anne Crouch, J. 2018. Clarireedia: A new fungal genus comprising four pathogenic species responsible for dollar spot disease of turfgrass. Fungal Biol. 122:761-773.

Sang, H., Hulvey, J., Popko, J. T., Lopes, J., Swaminathan, A., Chang, T., and Jung, G. 2015. A pleiotropic drug resistance transporter is involved in reduced sensitivity to multiple fungicide classes in Sclerotinia homoeocarpa. Mol. Plant Pathol. 16:251-261.

Sang, H., Popko, J., Chang, T., and Jung, G. 2017. Molecular mechanisms involved in qualitative and quantitative resistance to the dicarboximide fungicide iprodione in Sclerotinia homoeocarpa field isolates. Phytopathology 107:198-207.

Sanoamuang, N., and Gaunt, R. 1995. Persistence and fitness of carbendazim-and dicarboximide-resistant isolates of Monilinia fructicola (Wint.) Honey in flowers, shoots and fruit of stone fruit. Plant Pathol. 44:448-457.

Smiley, R. W., Dernoeden, P. P., and Clarke, B. B. 2005. Compendium of Turfgrass Diseases. American Phytopathological Society, St. Paul, MN.

Stephens, C. M., and Kaminski, J. E. 2019. In vitro fungicide-insensitive profiles of Sclerotinia homoeocarpa populations from Pennsylvania and the surrounding region. Plant Dis. 103:214-222.

Vargas, J. M. J., Golembiewski, R., and Detweiler, A. R. 1992. Dollar spot resistance to DMI fungicides. Golf Course Manage. 60:50-54.

Veturi, Y., Kump, K., Walsh, E., Ott, O., Poland, J., Kolkman, J. M., Balint-Kurti, P. J., Holland, J. B., and Wisser, R. J. 2012. Multivariate mixed linear model analysis of longitudinal data: An information-rich statistical technique for analyzing plant disease resistance. Phytopathology 102:1016-1025.

Walsh, B., Ikeda, S. S., and Boland, G. J. 1999. Biology and management of dollar spot (Sclerotinia homoeocarpa): An important disease of turfgrass. HortScience 34:13-21.

Warren, C. G., Sanders, P., and Cole, H. 1974. Sclerotinia homoeocarpa tolerance to benzimidazole configuration fungicides. Phytopathology 64: 1139-1142. 